Science, Technology and Development 35 (3): 141-147, 2016

ISSN 0254-6418 / DOI: 10.3923/std.2016.141.147

(C) 2016 Pakistan Council for Science and Technology

\title{
Investigating the Association of Arbuscular Mycorrhizal Fungi with Selected Ornamental Plants Collected from District Charsadda, KPK, Pakistan
}

\author{
${ }^{1}$ Tabassum Yaseen, ${ }^{1}$ Ayesha Naseer and ${ }^{2}$ Muhammad Shakeel \\ ${ }^{1}$ Department of Botany, Bacha Khan University, Charsadda, Pakistan \\ ${ }^{2}$ Department of Biotechnology, Bacha Khan University Charssada, Pakistan
}

\begin{abstract}
This study investigates Arbuscular Mycorrhizal Fungi (AMF) spore population and root colonization in 25 different ornamental families (35 species) collected from District Charsadda, at early winter and summer seasons. The spore density of AMF ranged from 23-80\% and root colonization from $0-100 \%$. The lowest spore density was recorded in Canna indica purpurea, Eriodictyon californicum, Lagerstroemia indica and the highest spore density was recorded in Jasminum sambc. The AMF root colonization was observed to be the lowest in Portulaca indica, Dracaena (Dragon tree) and the highest in Alocasia indica, Chlorophytum borivilianum, Eriodictyon californicum, Cesturnum nocturnum, Euphorbia milli. The present study also reports that roots of a few species of family Portulaceae have not been colonized by AMF. The spore density of AMF and root colonization by these fungi varied from species to species, season to season and also affected by host plant growth stages (vegetative-fruiting).
\end{abstract}

$\underline{\text { Key words: Arbuscular mycorrhizal fungi, root infection, spores density, ornamental plants, district charsadda }}$

\section{INTRODUCTION}

Ornamental plants are plants that are normally grown for ornamental purpose and not expected to be used for their nutritional value. These plants have enormous contribution towards horticultural industry and play important role in our daily life (Chandler, 2013). The term mycorrhiza is rooted from two Greek words "myco" means fungus and "rhiza" means root. Mycorrhiza is described as a mutual sharing of life; whereby the fungus is the major partner of the plant that supply food, growth hormones and protection to plant roots from pathogens and the plant in return offers high energetic material to the fungus (Alizadeh, 2011). The AM fungi form mutualistic association with majority of land plants and provide several advantages to host plants (Krishnakumar et al., 2013).

Plants have always been important in human history as a source of food, feed, medication and housing. Due to increased use of flowers, ornamental plants are getting more attention worldwide. Several conventional and biotechnological approaches have been practiced to enhance the quality and quantity of ornamental plants (Brundrett, 2002).

The AM fungi are obligate symbiont, which cannot be grown without living plant host. They have been shown to improve plant growth, due to increased uptake of phosphorous (P) and other essential nutrients (Requena et al., 2001). They have also been demonstrated in reduced soil erosion, due to improved water absorption (Dhar and Mridha, 2003), reduced disease occurrence, salt and drought tolerances (Evelin et al., 2009; Tonin et al., 2001). Among the ornamental plants, Petunia (Petunia hybrida) is very common and widespread in Riyadh, as it can be grown under reduced irrigation and high temperature. Not much is known whether petunia form mutualistic association with AM fungi (Gaur et al., 2000; Shamshiri et al., 2012; Reddy et al., 2009).

The critical factors, involved in the sustainable production of mycorrhizal ornamental plants, are the choices of growth substrate and fertilizing method. Therefore, this study investigated the effects of commercially available arbuscular mycorrhizal inocula and mode of organic mineral fertilization on mycorrhizal colonization and growth of three species of ornamental conifers, under a nursery-container production system (Falkowski and Matysiak, 2010).

\section{MATERIALS AND METHODS}

Study site: The present study was performed in various parts of Charsadda, Khyber Pakhtunkhwa, situated $34^{\circ} 8^{\prime} 43 \mathrm{~N}-71^{\circ} 43^{\prime} 51 \mathrm{E}$, with an elevation of $276 \mathrm{~m}$. The climatic conditions in District Charsadda are harsh, as there is little rainfall throughout the year, with an average temperature of $22.5^{\circ} \mathrm{C}$. The average annual rainfall is $460 \mathrm{~mm}$.

Collecting soil samples: Soil samples, containing spores and roots from the colonized 35 ornamental and medicinal plants, were retrieved during the study (Table 1). The 
Sci. Technol. Dev., 35 (3): 141-147, 2016

Table 1: Detailed information regarding plant species, families, growth stage and collection date

\begin{tabular}{|c|c|c|c|c|}
\hline Plant species & Family & Growth stage & Season & Date of collection \\
\hline Portulaca grandiflora & Portulacaceae & Flowering & Winter & 20.11 .2014 \\
\hline Calendula officinales (tagetes) & Asteraceae & Flowering & Winter & 20.11 .2014 \\
\hline Chrysanthemum indicus & Asteraceae & Flowering & Winter & 15.02 .2015 \\
\hline Coreopsis lenceolata & Asteraceae & Flowering & Summer & 17.05.2015 \\
\hline Gladiolus dalenii & Iridaceae & Fruiting & Winter & 20.11.2014 \\
\hline Aloe vera & Xanthorrhoeaceae & Mature & Summer & 15.05.2015 \\
\hline IVY ( Hedera) & Araliaceae & Fruiting & Winter & 21.11.2014 \\
\hline Tradescantia pallida & Commelinaceae & Flowering & Summer & 15.05. 2015 \\
\hline Celosia cristata & Amaranthaceae & Flowering & Winter & 21.11.2014 \\
\hline Alternethra purple knight & Amaranthaceae & Flowering & Winter & 26.12.2014 \\
\hline Amaryllis ( Hippeastrum) & Amaryllidaceae & Flowering & Summer & 15.05.2015 \\
\hline Narcissus poeticus & Amaryllidaceae & Flowering & Winter & 14.12.2014 \\
\hline Cynodon dactylon & Poaceae & Fruiting & Winter & 5.01 .2015 \\
\hline Cymbopogon & Poaceae & Vegetative & Winter & 22.02.2015 \\
\hline Duranta erecta & Verbenaceae & Fruiting & Summer & 15.05.2015 \\
\hline Duranta (Golden duranta) & Verbenaceae & Fruiting & Winter & 26.11.2014 \\
\hline Jasminum officinale & Oleaceae & Flowering & Winter & 22.02.2015 \\
\hline Jasminum humile & Oleaceae & Flowering & Winter & 22.02.2015 \\
\hline Jasminum sambac & Oleaceae & Flowering & Winter & 22.11.2014 \\
\hline Epipremnum aureum & Araceae & Vegetative & Winter & 16.01.2015 \\
\hline Alocasia indica & Aracaceae & Fruiting & Winter & 28.11.2014 \\
\hline Dypsis Lutescens & Aracaceae & Vegetative & Winter & 28.11.2014 \\
\hline Chlorophytum & Asparagaceae & Flowering & Winter & 25.02.2015 \\
\hline Dracaena (Dragon tree) & Asparagaceae & Flowering & Winter & 27.11.2014 \\
\hline Canna indica purpurea & Cannaceae & Flowering & Summer & 15.05.2015 \\
\hline Eriodictyon californicum & Boraginaceae & Vegetative & Summer & 15.03.2015 \\
\hline Lagerstroemia speciosa & Lythraceae & Fruiting & Winter & 25.02.2015 \\
\hline Gardenia jasminoides & Rubiaceae & Fruiting & Winter & 20.02.2015 \\
\hline Bryophyllum delagoense & Crassulaceae & Flowering & Summer & 16.05.2015 \\
\hline Senegalia Senegal & Febaceae & Flowering & Winter & 22.11.2014 \\
\hline Pittosporum tobira & Pittosporaceae & Flowering & Summer & 15.05 .2015 \\
\hline Cesturnum nocturnum & Solanaceae & Fruiting & Winter & 17.01.2015 \\
\hline Chamaecyparis lawsoniana & Cupressaceae & Fruiting & Winter & 26.11.2014 \\
\hline Araucaria araucana & Araucariaceae & Fruiting & Winter & 27.11.2014 \\
\hline Euphorbia milli & Euphorbiaceae & Flowering & Winter & 26.12.2014 \\
\hline
\end{tabular}

collected soil and root samples, from each of the plant studied, were used for isolation of AMF spores and studying related features.

AMF spores isolation and their quantification: The spores of AM fungi were isolated by "Wet Sieving and Decanting Technique" demonstrated by Gerdemann and Nicolson (1963). The isolated AMF spores were quantified, using Grid Line Intersect Method (Gaur and Adholeya, 1994). The pictures of the spores being counted were taken, using Nikon Coolpix S6200.

Identification of AMF spores: The spores of AM fungi were identified, using the guidelines given by the earlier studies (Morton and Benny, 1990; Mukerji, 1996; Schenck and Perez, 1990; Morton and Redecker, 2001; Sharma et al., 2009; Kumar et al., 2009). The identification of these fungi was done, following the manual of Schenck and Perez (1990) and was also compared with reference species description demonstrated by INVAM (International culture collection of vesicular arbuscular mycorrhizal fungi). For the characterization of AM fungi, various characteristics of spores, such as, morphology, shape, color and size, were studied. For examining the spore size and shape up to 50 spores were taken in a drop of lactic acid. The dimensions of spores were determined, using micrometry.

Root clearing and staining technique: For roots cleaning and staining, a method, reported by Phillips and Hayman (1970) and Kormanik et al. (1980), was used.

Separation and quantification of spores: The AMF spores from the $100 \mathrm{gm}$ roots zone soil were isolated using wet sieving and decanting method (Gerdemann and Nicolson, 1963). The rhizospheric soil for a particular plant was obtained from different spots, pooled and then mixed to take representative soil sample. Each sample was taken in triplicate and data represented as mean spore density/100 gm soil with standard deviation. The total number of spores obtained by wet sieving was referred to as Spore density. Quantification of spores was performed employing the procedure reported by Lugo and Cabello, (2002) in petri plate of $10 \mathrm{~cm}$ diameter with gridline of $1 \mathrm{~cm}$ square taking help of stereoscopic microscope at $100 x$. In this study, we counted 10 divisions and relate it to total number of spores employing the procedure, given by McKenney and Lindsey (1987). 
Root colonization analysis: The colonization of AM fungi and its extent was demonstrated from the randomly chosen root tissue of each plant studied using frequency distribution method (Biermann and Lindermann, 1981). For this purpose, roots were cut in $1 \mathrm{~cm}$ segments, cleared and stained. The stained roots' samples were visualized, using compound microscope for monitoring fungal structures like vesicles, hyphae or arbuscule, etc.

Percent root colonization for each plant was calculated using following relation.

\section{RESULTS AND DISCUSSION}

This study shows that 33 out of 35 species examined were mycorrhizal fungi. The present work reports that the 35AMF species linked with the ornamental plants are broadly disseminated among 3 genera, i.e., Genus Glomus, acaulospora and Sclerocystis, characterized by all species, respectively. The limited AMF generic diversity shown for District Charsadda is encouraging and needs to be further explored.

In our study, only genus Sclerocystis has been reported to present high adaptation with ornamental plants. Since the total AMF species enumerated here belong to this genus and the remaining are characterized by the other two genera of Glomus and Acaulospora. The results indicated that 33 out of 35 Ornamental plants, examined during the study, exhibited the presence of arbuscular mycorrhizal association. The root colonization range in AMF is assumed to be variable which range from very low of $20 \%$ in Alternethra purple knight (family Amaranthaceae) and Duranta erecta (family Verbenaceae) to the highest of $100 \%$ in Eriodictyon californicum (family Boraginaceae), Euphorbia milli (family Euphorbiaceae), Cesturnum nocturnum (family Solanaceae), Eriodictyon californicum (family Boraginaceae) and Chlorophytum borivilianum (family Asparagaceae). Only 4, out of 35 plants' species, have $0-20 \%$ root colonization, 13 plant species have 30-60\% colonization, 9 species show AMF root colonization between $60-80 \%$ and the other 9 have shown $80-100 \%$ root colonization.

Spores density: The spore density of AMF ranged from $23-80 \%$ in the rhizospheric soil of 25 different ornamental families (35 species). Different morphotypes of AMF corresponding to two orders were recorded from the rhizosphere, i.e., Acaulospora species, Glomus species (Fig. 2). These results have demonstrated that Glomus was the dominant specie. These results are in agreement with the results, obtained by Burni et al. (2013), which show that Glomus species were dominant, followed by Acaulospora and Sclerocystis in Aloe vera (Xanthorrhoeaceae). The results were also comparable with the results of Zandavalli et al. (2004), who have reported the presence of Glomus clarum in A. angustifolia, Glomus pansihalus in Jasminum sambac (Fig. 1c), Glomus amphisporum in Hedra helix (Fig. 1d),
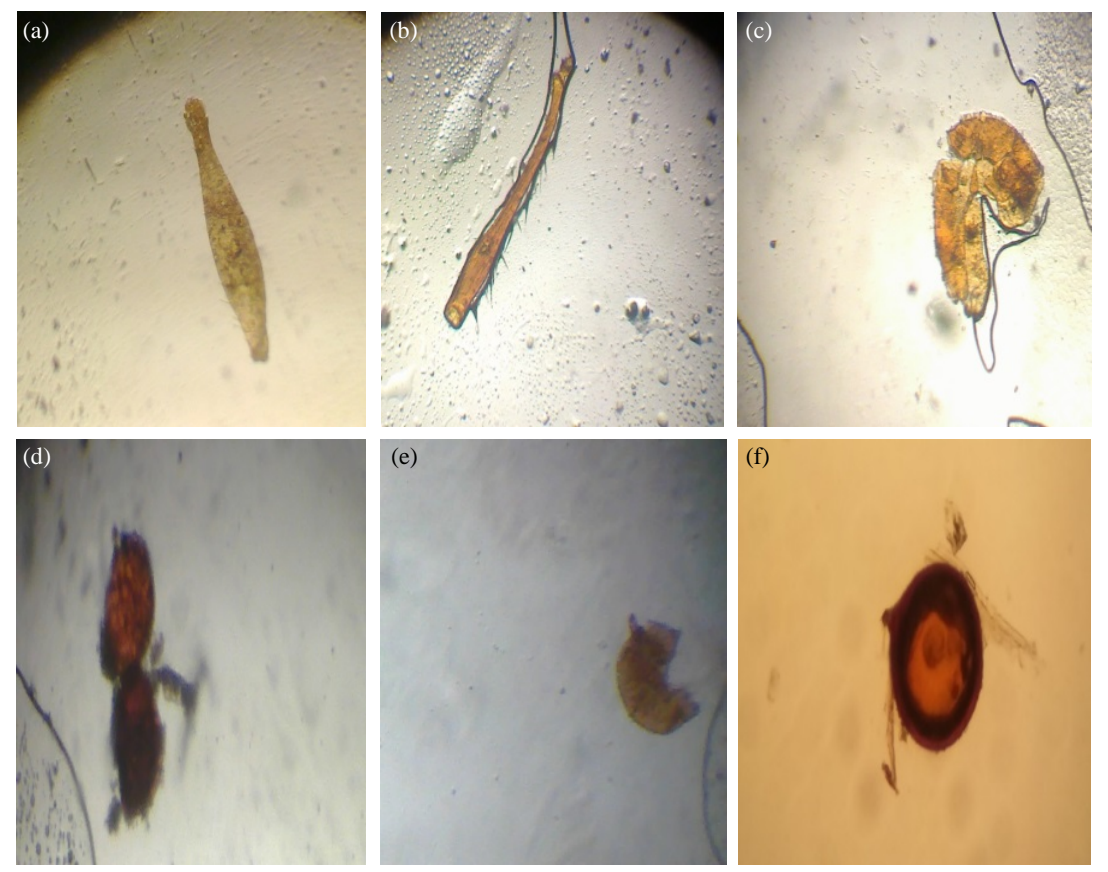

Fig. 1(a-f): AMF spores in ornamental plants, (a) Schlerocystis spp., (b) Schlerocystis spp., (c) Glomus pansihalus, (d) Glomus amphisporum, (e) Glomus multisubstensum and (f) Acaclospora mellea 


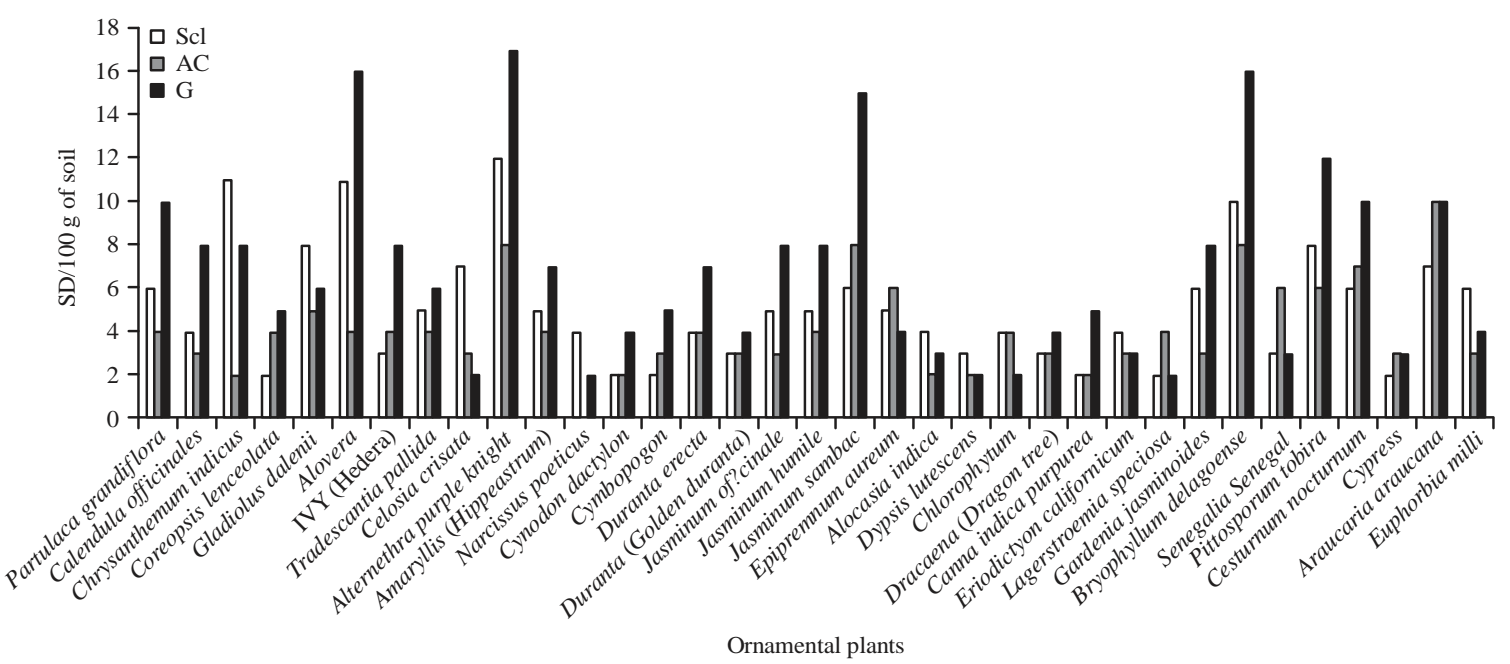

Fig. 2: Spore Density (SD) of each of three AMF species G: Glomus species, AC: Aculospora species, Scl: Sclerocystis species) associated with ornamental plants species in District Charsadda, Khyber Pakhtunkhwa

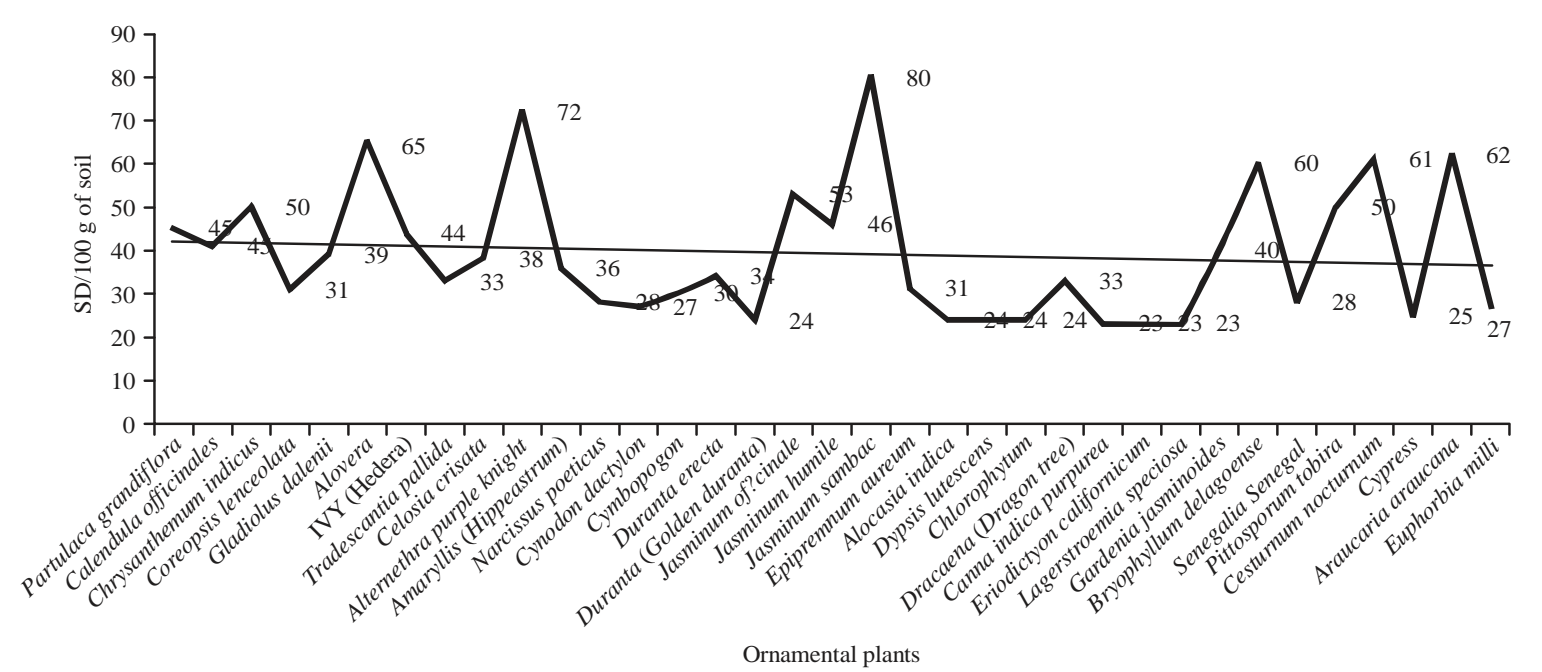

Fig. 3: Total spore density of AMF associated with the species of ornamental plants studied from the District Charsadda, KPK

Glomus multisubstensum in Chrysanthemumindicus (Fig. 1e), schlerocystis spp., in Narcissus poeticus (Fig. 1a-b) and Acaclospora melleain Trasdacntia indica (Fig. 1f). These results were supported by the results of Younis et al. (2013), reporting the number of spores found in the root zones of Tetraclinis articulate (Cupressaceae) and O. oleaster (Oleaceae) with spores of 3 different genera of AM fungi (Glomus, Scutellospora and Acaulospora). The lowest spore density was recorded in Canna indica purpurea, Eriodictyon californicum, Lagerstroemia indica and the highest spore density was recorded in Jasminum sambc (Fig. 3). These findings also support the findings of Kumar et al. (2012), who intimated the presence of Glomus, Acaulospora and
Sclerocystis in Aster amellus (Asteraceae). Zaman et al. (2008a) have also demonstrated the AMF spore density in the compositae.

Root colonization: The AM fungi are considered to be an essential part of sustainable agriculture, playing a role in the recovery of agriculture land and bared habitats for both classical and new crops (Wang and Qiu, 2006). They have received significant attention in agriculture especially in the field of horticulture. These fungi have been reported to form a key ecological and economical cluster of soil borne fungi which establish mutualistic relationship with most of the plant families. 
Sci. Technol. Dev., 35 (3): 141-147, 2016

Table 2: Percentage of frequency occurrence of AM fungi in the rhizosphere soils of ornamental plants of Charsadda

\begin{tabular}{|c|c|c|c|c|c|c|}
\hline \multirow[b]{2}{*}{ Families } & \multirow[b]{2}{*}{ Species } & \multicolumn{4}{|c|}{ Root infections } & \multirow[b]{2}{*}{ Frequency (\%) } \\
\hline & & E H. & $\mathrm{IH}$. & Arb. & Ves. & \\
\hline Portulacaceae & Portulaca indica & - & - & - & - & 0.0 \\
\hline \multirow[t]{3}{*}{ Asteraceae } & Calendula officinales & ++ & - & - & ++ & 75.0 \\
\hline & Chrysanthemum indicus & + & + & - & + & 75.0 \\
\hline & Coreopsis lenceolata & +++ & - & + & ++ & 80.0 \\
\hline Iridaceae & Gladiolus dalenii & ++ & ++ & - & - & 50.0 \\
\hline Xanthorrhoeaceae & Aloe vera & +++ & ++ & - & + & 70.0 \\
\hline Araliaceae & (Hedera) & +++ & ++ & - & ++ & 87.5 \\
\hline Commelinaceae & Tradescantia pallida & - & +++ & - & +++ & 80.0 \\
\hline \multirow[t]{2}{*}{ Amaranthaceae } & Celosia cristata & +++ & - & - & - & 66.0 \\
\hline & Alternethra purple knight & ++ & ++ & - & - & 20.0 \\
\hline \multirow[t]{2}{*}{ Amaryllidaceae } & Amaryllis & + & ++ & - & + & 60.0 \\
\hline & Narcissus poeticus & + & + & - & - & 50.0 \\
\hline \multirow[t]{2}{*}{ Poaceae } & Cynodon dactylon & - & - & - & - & 50.0 \\
\hline & Cymbopogon & ++ & ++ & - & ++ & 66.0 \\
\hline \multirow[t]{2}{*}{ Verbenaceae } & Duranta erecta, & + & + & - & ++ & 20.0 \\
\hline & Duranta & + & ++ & - & + & 40.0 \\
\hline \multirow[t]{3}{*}{ Oleaceae } & Jasminum officinale, & + & ++ & - & - & 50.0 \\
\hline & Jasminum humile & ++ & +++ & - & - & 66.6 \\
\hline & Jasminum sambac & ++ & ++ & + & - & 50.0 \\
\hline Araceae & Epipremnum aureum & + & - & - & +++ & 33.3 \\
\hline \multirow[t]{2}{*}{ Aracaceae } & Alocasia indica, & - & ++ & - & - & 100.0 \\
\hline & Dypsis Lutescens & + & ++ & - & + & 50.0 \\
\hline \multirow[t]{2}{*}{ Asparagaceae } & Chlorophytum borivilianum & - & - & - & - & 100.0 \\
\hline & Dracaena & ++ & ++ & + & - & Nill \\
\hline Cannaceae & Canna indica purpurea & ++ & - & - & - & 33.3 \\
\hline Boraginaceae & Eriodictyon californicum & + & ++ & - & ++ & 100.0 \\
\hline Lythraceae & Lagerstroemia speciose & ++ & ++ & - & - & 50.0 \\
\hline Rubiaceae & Gardenia jasminoides & +++ & ++ & - & + & 75.0 \\
\hline Crassulaceae & Bryophyllum delagonse & +++ & ++ & + & - & 90.0 \\
\hline Febaceae & Senegalia Senegal & +++ & +++ & - & + & 80.0 \\
\hline Pittosporaceae & Pittosporum tobira & ++ & ++ & - & - & 83.3 \\
\hline Solanaceae & Cesturnum nocturnum & ++ & ++ & - & ++ & 100.0 \\
\hline Cupressaceae & Chamaecyparis lawsoniana & - & + & + & - & 50.0 \\
\hline Araucariaceae & Araucaria araucana & ++ & ++ & - & - & 50.0 \\
\hline Euphorbiaceae & Euphorbia milli & - & ++ & ++ & +++ & 100.0 \\
\hline
\end{tabular}

Nill: -, Low: +, Medium: ++, High: +++ EH: External Hyphae, IH: Internal hyphae, Arb.: Arbuscules, Ves.: Vesicales

In the studied plants, root colonization was reported from $0-100 \%$. No colonization in the roots of chlorophytum borivilianum by AM fungi was reported here (Table 2). Our results matched with the results of Silva and Yapa (2010), who have reported maximum root colonization in Asparagus racemosus. The present study has also reported 50\% root colonization in Gladiolus dalenii, $75 \%$ colonization each in Calendula officinali and Chrysanthemum indicus (Table 2). These results also support the results of Kumar et al. (2012), who also examined AMF root colonization and spore density in Crysanthemum leucanthemum and Gladiolus grandifloras. Root colonization reported in Aloe vera in our study was $70 \%$ (Table 2), which is closer to 95\% reported by Burni et al. (2013). These results were also supported by results of Burni and Hussain (2011), in families like Alocasia indica (100\%), cynodon dactylon (50\%), cymbopogon (50\%), Euphorbia milli (100\%), Senegalia Senegal (80\%), Gardenia jasminoides (75\%) and Cesturnum nocturnum (100\%). Our results of getting more vesicles, arbuscules and external hyphae (Table 2) were in agreement with results of Gorsi (2002) and Zaman et al. (2008b), who had reported 66.6\% AMF effect in Kalanchoe pinnata.

\section{CONCLUSION}

It is concluded from this study that biodiversity of AMF, spore density and root colonization by these fungi varied from species to species, season to season and also affected by host plant growth stages (vegetative-fruiting). Spore density when studied in summer and winter indicated that the dominant AMF endophytes and plant species in each season were different following great variation. When spore number were high, the percentage colonization was low but as spore number began to decline the colonization increased. The highest spore numbers were recorded during August to October, while most mycorrhizal colonization recorded during December to March. Fluctuations in spore numbers were attributed 
to seasonal variations. A variety of AM fungi were found in both seasons where Glomus species were found more frequently. There is a specificity of AMF, natural diversity of AM fungi in the soil differ from species to species and differently influence root colonization and spore density. The highest intensity of AM colonization and spore population in the flowering stage also explains the successful interaction of the plants with AM fungi. It was also observed that extra radical hyphae were more helpful in providing nutrients to host plant than do the root hairs.

\section{REFERENCES}

Alizadeh, O., 2011. Mycorrhizal symbiosis. Adv. Stud. Biol., 3: 273-281.

Biermann, B. and R.G. Linderman, 1981. Quantifying vesicular-arbuscular mycorrhizae: A proposed method towards standardization. New Phytol., 87: 63-67.

Brundrett, M.C., 2002. Coevolution of roots and mycorrhizas of land plants. New Phytol., 154: 275-304.

Burni, T. and F. Hussain, 2011. Diversity in arbuscular mycorrhizal morphology in some medicinal plants of family Lamiaceae. Pak. J. Bot., 43: 1789-1792.

Burni, T., S. Nasreen, T. Yaseen and S. Bibi, 2013. Arblscular mycorrhizal stuidies in 'Aloe vera (L). Burm. f.' biologically active and potential medicinal plant. Wudpecker J. Agric. Res., 2: 39-42.

Chandler, S., 2013. Genetically engineered ornamental plants: Regulatory hurdles to commercialization. ISB News Report, August 2013, Australia. http://www.isb.vt.edu/news/2013/Aug/Chandler.pdf

Dhar, P.P. and M.A.U. Mridha, 2003. Status of biodiversity of arbuscular mycorrhizal fungi in different tree species growing in Betagi community forests. Chittagong Univ. J. Sci., 27: 13-19.

Evelin, H., R. Kapoor and B. Giri, 2009. Arbuscular mycorrhizal fungi in alleviation of salt stress: A review. Ann. Bot., 104: 1263-1280.

Falkowski, G. and B. Matysiak, 2010. The use of arbuscular mycorrhizal fungi in container production of selected ornamental conifers under organic-mineral fertilization level. J. Fruit Ornamental Plant Res., 18: 335-348.

Gaur, A. and A. Adholeya, 1994. Estimation of VAM spores in the soil: A modified method. Mycorrhiza News, 6: 10-11.

Gaur, A., A. Gaur and A. Adholeya, 2000. Growth and flowering in Petunia hybrida, Callistephus chinensis and Impatiens balsamina inoculated with mixed AM inocula or chemical fertilizers in a soil of low $\mathrm{P}$ fertility. Sci. Horticult., 84: 151-162.
Gerdemann, J.W. and T.H. Nicolson, 1963. Spores of mycorrhizal Endogone species extracted from soil by wet sieving and decanting. Trans. Br. Mycol. Soc., 46: 235-244.

Gorsi, S.M., 2002. Studies on mycorrhizal association in some medicinal plants of Azad Jammu and Kashmir. Asian J. Plant Sci., 1: 383-387.

Kormanik, P.P., W.C. Bryan and R.C. Schultz, 1980. Procedures and equipment for staining large numbers of plant root samples for endomycorrhizal assay. Can. J. Microbiol., 26: 536-538.

Krishnakumar, S., N. Balakrishnan, R. Muthukrishnan and S.R. Kumar, 2013. Myth and mystery of soil mycorrhiza: A review. Afr. J. Agric. Res., 8: 4706-4717.

Kumar, A., S. Singh and A. Pandey, 2009. General microflora, arbuscular mycorrhizal colonization and occurrence of endophytes in the rhizosphere of two age groups of Ginkgo biloba L. of Indian Central Himalaya. Indian J. Microbiol., 49: 134-141.

Kumar, A., S.K. Bhatti and A. Aggarwal, 2012. Biodiversity of endophytic mycorrhiza in some ornamental flowering plants of Solan, Himachal Pradesh. Biol. Forum: Int. J., 4: 45-51.

Lugo, M.A. and M.N. Cabello, 2002. Native Arbuscular Mycorrhizal Fungi (AMF) from mountain grassland (Cordoba, Argentina) I. Seasonal variation of fungal spore diversity. Mycologia, 94: 579-586.

McKenney, M.C. and D.L. Lindsey, 1987. Improved method for quantifying endomycorrhizal fungi spores from soil. Mycologia, 79: 779-782.

Morton, J.B. and D. Redecker, 2001. Two new families of Glomales, Archaeosporaceae and Paraglomaceae, with two new genera Archaeospora and Paraglomus, based on concordant molecular and morphological characters. Mycologia, 93: 181-195.

Morton, J.B. and G.L. Benny, 1990. Revised classification of arbuscular mycorrhizal fungi (Zygomycetes): A new order, Glomales, two new suborders, Glomineae and Gigasporineae and two new families, Acaulosporaceae and Gigasporaceae, with an emendation of Glomaceae. Mycotaxon, 37: 471-491.

Mukerji, K.G., 1996. Concepts in Mycorrhizal Research. In: Handbook of Vegetation Science, Mukerji, K.G. (Ed.). Kluwer Academic Publishers, USA.

Phillips, J.M. and D.S. Hayman, 1970. Improved procedures for clearing roots and staining parasitic and vesicular-arbuscular mycorrhizal fungi for rapid assessment of infection. Trans. Br. Mycol. Soc., 55: 158-161. 
Reddy, D.M.R.S., S. Svistoonoff, F. Breuillin, S. Wegmuller, M. Bucher and D. Reinhardt, 2009. Development and Function of the Arbuscular Mycorrhizal Symbiosis in Petunia. In: Petunia: Evolutionary, Developmental and Physiological Genetics, Gerats, T. and J. Strommer (Eds.). 2nd Edn., Springer, New York, ISBN: 978-0-38784795-5, pp: 131-156.

Requena, N., E. Perez-Solis, C. Azcon-Aguilar, P. Jeffries and J.M. Barea, 2001. Management of indigenous plant-microbe symbioses aids restoration of desertified ecosystems. Applied Environ. Microbiol., 67: 495-498.

Schenck, N.C. and Y. Perez, 1990. Manual for the Identification of VA Mycorrhizal Fungi. 3rd Edn., Synergistic Publications, Gainesville, FL., ISBN-13: 9780962598036, Pages: 286.

Shamshiri, M.H., K. Usha and S. Bhupinder, 2012. Growth and nutrient uptake responses of Kinnow to vesicular arbuscular mycorrhizae. ISRN Agron. 10.5402/2012/535846

Sharma, D., R. Kapoor and A.K. Bhatnagar, 2009. Differential growth response of Curculigo orchioides to native Arbuscular Mycorrhizal Fungal (AMF) communities varying in number and fungal components. Eur. J. Soil Biol., 45: 328-333.

Silva, K.S.N. and P.N. Yapa, 2010. The status of vesicular arbuscular mycorrhizal associations with medicinal plants in mihintale sanctuary. Proceedings of the 15th International Forestry and Environment Symposium, November 26-27, 2010, Department of Forestry and Environmental Science, University of Sri Jayewardenepura, Sri Lanka.
Tonin, C., P. Vandenkoornhuyse, E.J. Loner, I. Straczek and C. Leyval, 2001. Assessment of arbuscular mycorrhizal fungi diversity in the rhizosphere of Viola calaminaria and effect of these fungi on heavy metal uptake by clover. Mycorrhiza, 10: 161-168.

Wang, B. and Y.L. Qiu, 2006. Phylogenetic distribution and evolution of mycorrhizas in land plants. Mycorrhiza, 16: 299-363.

Younis, A., A. Riaz, M. Sajid, N. Mushtaq and M. Ahsan et al., 2013. Foliar application of macro- and micronutrients on the yield and quality of Rosa hybrida cvs. Cardinal and Whisky Mac. Afr. J. Biotechnol., 12: 702-708.

Zaman, K., E. Roy, S.E. Arifeen, M. Rahman and R. Raqib et al., 2008a. Effectiveness of maternal influenza immunization in mothers and infants. N. Engl. J. Med., 359: 1555-1564.

Zaman, P., A.K. Roy, N.S. Khanum, N. Absar and T. Yeasmin, 2008b. Arbuscular mycorrhizal status of medicinal plants in Rajshahi University campus. Mycosystema, 27: 543-553.

Zandavalli, R.B., L.R. Dillenburg and P.V. de Souza, 2004. Growth responses of Araucaria angustifolia (Araucariaceae) to inoculation with the mycorrhizal fungus Glomus clarum. Applied Soil Ecol., 25: 245-255. 